\title{
sciendo
}

\section{Intelligent Personal Assistant in Business- Context: Key-feature Evaluation for User Acceptance}

\author{
Daniel Hüsson \\ UCAM - Catholic University of Murcia, Spain \\ Alexander Holland \\ FOM University of Applied Sciences Essen, Germany \\ Rocío Arteaga Sánchez \\ UCAM - Catholic University of Murcia, Spain
}

\section{Abstract}

Background: The usage of intelligent personal assistants (IPA), such as Amazon Alexa or Google Assistant is increasing significantly, and voice-interaction is relevant for workflows in a business context. Objectives: This research aims to determine IPA characteristics to evaluate the usefulness of specific functions in a simulated production system of an Enterprise Resource Planning (ERP) software. A new function called explanation-mode is introduced to the scientific community and business world. Methods/Approach: As part of a design science research, an artefact, i.e. an add-on for speech-interaction in business software, was developed and evaluated using a survey among ERP users and researchers. Results: In the area of IPA-features, the search-function and speech input for textual fields were recognised as most useful. The newly introduced feature, the explanation mode, was positively received too. There is no significant correlation between the usefulness of features and participantcharacteristics, affinity to technology or previous experience with IPAs in a private context, which is in line with previous studies in the private environment leading to the conclusion that the task attraction is the most important element for usefulness. Conclusions: Most of the participants agreed that the speech-input is not able to fully substitute standard input devices, such as a keyboard or a mouse, so the IPA is recognised as an addition to traditional input methods. The usefulness is rated high especially for speech-input for long text fields, calling up masks and search-functions.

Keywords: intelligent personal assistant, human-computer-interface, enterpriseresource-planning, machine learning, business process, natural language processing JEL classification: $\mathrm{O} 3, \mathrm{O} 31, \mathrm{O} 32, \mathrm{O} 33$

Paper type: Research article

Received: 16 Jun 2020

Accepted: 6 Jul 2020

Citation: Hüsson, D., Holland, A., Arteaga Sánchez, R., (2020), "Intelligent Personal Assistants in Business-Context: Key-feature Evaluation for User Acceptance", Business Systems Research, Vol 11 No 3, pp. 147-166.

DOI: https://doi.org/10.2478/bsri-2020-0032 


\section{Introduction}

With intelligent personal assistants (IPA) like Amazon Alexa or Google Assistant, a new area of user-interaction has approached, superseding the user-input by keyboard, mouse and touchscreen with control systems by voice commands, starting workflows and guide the user through complex processes and decision making via speech synthesis (Doss et al., 2018). Influenced by the experience in the private use of IPA functions, users are looking for equivalent comfort in business applications to control processes, resulting in an increasing number of IPA users in the business environment (Budzinski et al., 2018; Saran, 2018). For instance, Amazon initiates Alexa for business issues by integrating Microsoft Office 365 to access and control the scheduler via voice control (Amazon, 2019). Enabled by improvements in artificial intelligence, tools are able to foster better interaction between human and machine, but the main indicators for continued use and satisfying user experience are not discovered well enough (Yang \& Lee, 2019).

Previous researches set the focus on private (Cowan et al., 2017) or educational (Babicet al., 2018) use of IPAs, also the specific use of certain IPA features and the satisfaction rate have been examined (Lopatovska et al., 2019), but there is no research investigation concerning the usage and recommendation of IPA-features in a business context, leading to a need to identify relevant features in the context mentioned above. From this the main research question of this article is derived:

"Which specific Al-features in the field of IPA are being recognised as applicable in a business context?"

In order to contribute to this question and underlying research gap, the purpose of the paper is to analyse specific use-cases and work out which features can benefit from an IPA-Implementation to cover existing weak points in process flows in terms of usability, especially in navigation, information overload and lack of system communicativeness derived from the literature (Lambeck et al., 2014a, 2014b; Wong et al. 2016). This article also addresses the findings from previous researches regarding challenges of ERP-implementation in terms of general usability, resulting in a high need of user training to enable users to manage the system (ElFarmawi, 2019) and the impact of data on decision making (Potančok, 2019).

To analyse the specific user-requirements and the acceptance of speechworkflows in business context a prototype for an IPA was developed and implemented in a state of the art web-based ERP system as an additional module (Hüsson \& Holland, 2019a). The prototype was named V-IP-A and is fully web-based, for easy distribution and evaluation, with less installation complexity. The only necessary precondition is the usage of the browser chrome, due to the ready-to-use speech-framework web speech API (WSA) introduced by the W3C Community in 2012 (Shires \& Jägenstedt, 2018; Wedekind, 2018).

As part of a design science research approach, the artifact was introduced, applied and discussed with the academic community in different national and international conferences (Hüsson, 2019a; Hüsson \& Holland, 2019a, 2019b). Feedback from the conferences helped to narrow the scope of the research project and working out key indicators for user acceptance and relevant features. In order to close the gap to the business context, the artifact was also introduced to a professional audience during a business summit in September 2019 in Krefeld, Germany (Hüsson, 2019b). Based on the artifact an evaluation method for features and useracceptance was derived and discussed (Hüsson \& Holland, 2019b).

Due to the feedback from the academic and business fields, a new version 1.1 of the artifact was developed including the functionality to enter notes by voice input which was requested as the most useful feature by business users (Hüsson, 2019b, 24), 
and a corresponding version of the questionnaire was created and provided to experienced ERP system-users. The participants got access to the IPA-artifact and were enabled to work with the IPA in an ERP-environment to gather insights into the usage in a simulated productive system. The questionnaire was sent to 500 ERP systemusers and researchers in different user-levels and departments.

This article contains novel theoretical and practical contributions. On one hand, the authors adapt and develop IPA-features in a business context based on existing research gaps. This paper contributes new insights to the existing literature by introducing a new user-experience-item called explanation-mode to IPAs in a business context extending the level of interaction between the user and the ERP system. In addition, the authors are verifying findings from studies in the private environment regarding main drivers for usefulness of IPA according to the task attraction. On the other hand, this article provides an empirical analysis of the usefulness and useracceptance of the implemented features of IPAs in the business context based on a fully functional prototype.

In the next section, the authors presents the theoretical framework. The third section describes the research method and presents the data analysis as well as the results. Then, the paper discusses the results and, finally, conclusions are presented.

\section{Literature review}

Based on fundament literature research speech recognition is the result of almost 70 years of research starting in the early 1950 s by understanding digits of the ten-digit series (Davis et al., 1952) paving the way for conversational agent, that started in the 2010s, when the first IPAs like Cortana or Alexa were introduced to the market (Yang \& Lee, 2019). Due to the complexity of languages and individual pronunciation, much research was needed to leverage speech recognition from the recognition of single numbers to whole sentences and to interact with users via speech synthesis, which in turn enabled intelligent dialogue systems such as Siri or Alexa (Juang \& Rabiner, 2004; Knote et al., 2019). Automatic speech recognition in combination with speech synthesis enables a wide range of opportunities in interacting with the user, but actually, the main tasks fulfilled by IPAs are simple information retrievals or service executions in a private context, such as setting a timer, playing songs, readings news or controlling smart devices (Gnewuch et al., 2017; Knote et al., 2019; Yang \& Lee, 2019). As stated in the introduction the personal use of IPAs is already affecting the demands in business contexts, leading to a necessity to understand what type of tasks can be supported by IPAs and what are the key indicators for valuable features and high user acceptance. The literature usually addresses two groups of challenges to determine the acceptance of an IPA (Sarikaya, 2017):

1. User experience challenges such as operational errors, lack of competence and privacy and security concerns

2. Technical challenges like experience scaling, speech-recognition challenges, language understanding and different devices.

In related studies, five fundamental objectives for maximizing the value of IPAs were discovered: efficiency, convenience, ease of use, enjoyment and reduced cognitive effort (Rzepka, 2019). Other researches in the field of para-social relationships found that the most important construct for user satisfaction is task attraction, indicating the user's perception of an IPA to complete given tasks as a reliable work partner (Han \& Yang, 2018). On the other hand, researches in the field of user acceptance in ERP systems are pointing out significant issues in terms of usability, especially in navigation, information overload and lack of system communicativeness (Lambeck et al., 2014a, 2014b; Wong et al., 2016). Since most of the IPA studies are working on theoretical 
background and focusing on the private use of IPAs it is important to investigate the user interaction and impact on usability in real-world business scenarios to get a full picture of the IPAs potential to solve user interface issues in ERP systems.

\section{Methodology}

As mentioned in the introduction, this study is part of a design science research project investigating the impact of artificial intelligence on business processes in SMEs. The prototype is designed as an artifact in the field of action design research (Sein et al., 2011 ) connecting the business requirements regarding the usability of an ERP system with the academic requirements of an output of design ensembles that contribute to the know-how for developing specific artifacts (Peffers et al., 2018). Previous studies discovered that perceived usefulness is one of the most important extrinsic and utilitarian values (Hsu et al., 2014; Kalinic \& Marinkovic, 2016). Especially when it comes to modern technologies such as smartphones or mobile applications, the perceived usefulness and necessity is strongly influencing the usage intention (Park \& Chen, 2007; Mohd Suki \& Mohd Suki, 2017). Beside usefulness, the perceived enjoyment is also recognized as an intrinsic motivation for adopting technology products (Venkatesh, 2000; Yang et al., 2016). Since the focus of this study is the business use of IPAs and prior research in the area of personal assistants underpins the importance of usefulness over enjoyment (Yang \& Lee, 2019), the main emphasis was set to evaluate the most useful features of the IPA and to get suggestions for not yet implemented features with a high level of usefulness.

\section{Artifact development}

For the purpose of evaluation, the prototype of an IPA was fully integrated into a webbased ERP-system and can be activated with a button, as presented in Figure 1. By using a button instead of a hot-word-detection like "Alexa" or "OK Google" the security concerns regarding privacy (Manikonda et al., 2017) can be reduced because the IPA does not have to listen continuously for a hot word detection.

Figure 2 illustrates the system architecture focussed on the interaction between users, WSA and ERP-components (Vemas.NextGen), working out the different elements to transfer information and respond to the user command.

By combining voice input and output with a display, the full range of audio- and visual interaction can be provided, levelling up the user experience and the way ERP systems can interact with users (Nishimura et al., 2018; Saran, 2018). Contributing to the usage-pattern in private context as worked out in the previous chapter, the IPA supports short commands for information retrieval and task execution. During the development of the voice assistant, guidelines (Murad et al., 2018, 2019) were taken into account, to create a state-of-the-art user experience to reduce the risks and training cost for ERP-implementations (ElFarmawi, 2019). Table 1 gives a brief summary of the IPAs functions for user-interaction, derived from the research based on detailed and previously mentioned literature research, feedback of conferences and businesssummit participants as explained later in this chapter. 
Figure 1

Start screen intelligent personal assistant

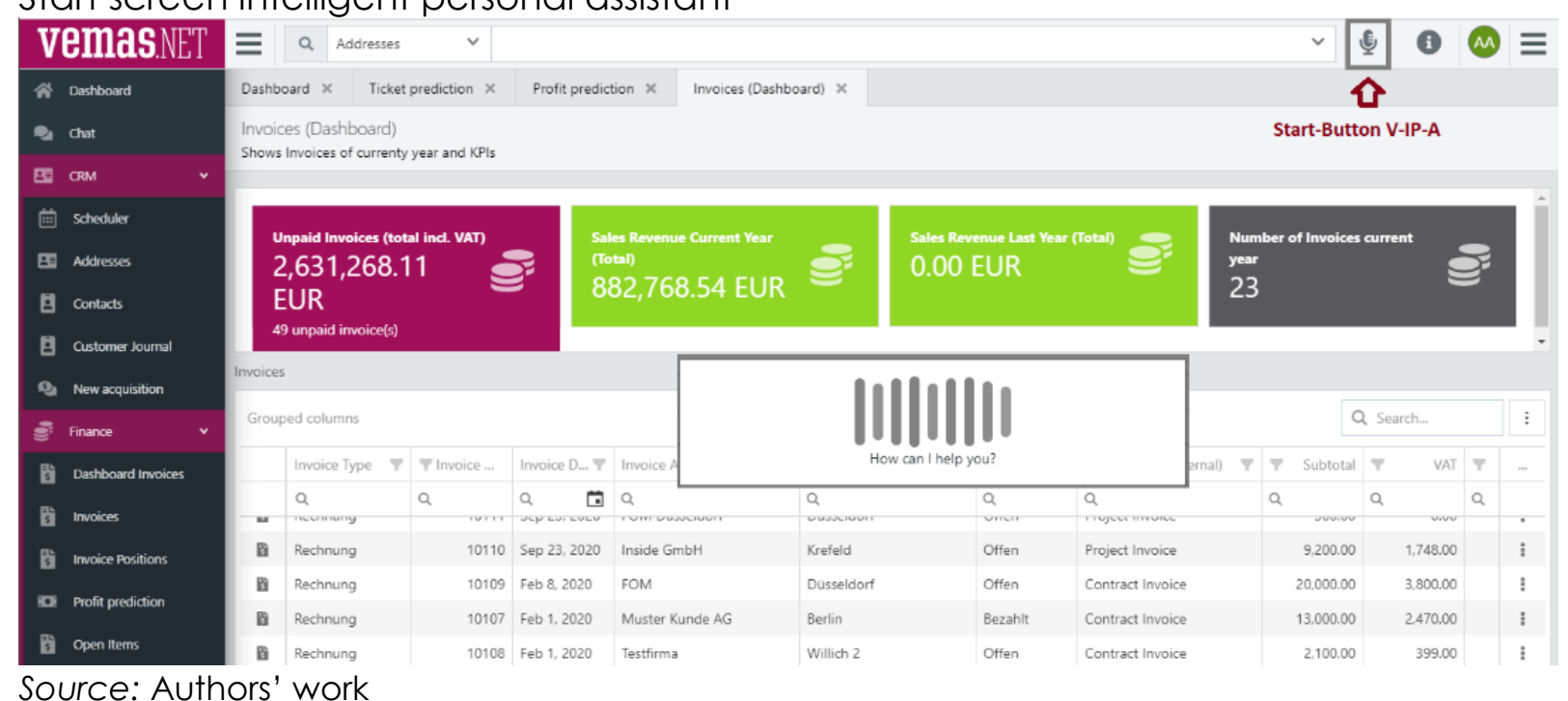

Figure 2

System architecture of V-IP-A and interaction flow

Browser: Chrome Vemas.NextGen Frontend Voice-Command Speech-to-Text
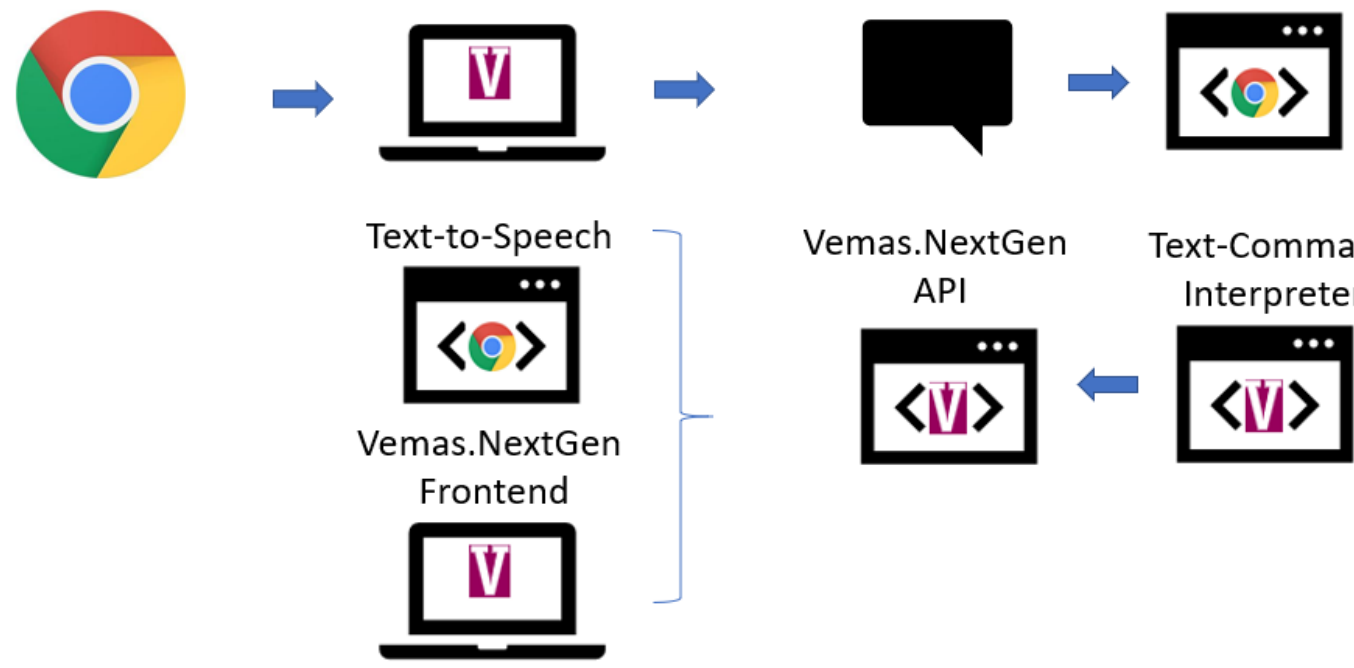

Vemas.NextGen API

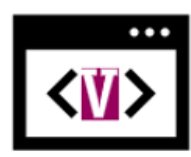

Text-Command Interpreter

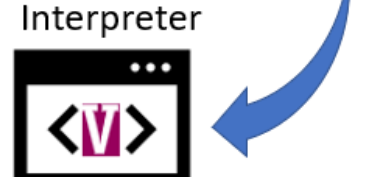

Source: Authors' work

Based on these functions, a set of commands was implemented to fulfil tasks within the ERP system. The chosen and implemented features were suggested by ERP-experts and ERP system-users and discussed with researchers and key-users during conferences (FOM Data Science February 2019 Düsseldorf Germany, 10th Conference Professional Knowledge Management March 2019 Potsdam Germany and 32nd Bled eConference - Humanizing Technology for a Sustainable Society June 2019 Bled Slovenia) and a business summit (Vemas.Inside September 2019 Krefeld, Germany). Based on this feedback the prototype has been developed until a final draft for the evaluation was deployed. 
Table 1

Functional overview IPA

\begin{tabular}{|c|c|c|}
\hline No. & Function & Description \\
\hline 1 & $\begin{array}{l}\text { Speech- } \\
\text { Commands }\end{array}$ & $\begin{array}{l}\text { Analysing speech for keywords to trigger actions like opening a } \\
\text { specific form or report. The speech must be divided into commands } \\
\text { and parameter for the command. } \\
\text { Limitation: Only one command at a time, the commands are } \\
\text { predefined and addressable by keywords, but extendable by add- } \\
\text { ons. Recognizing the personal name, e.g. for searching for a } \\
\text { company or contact person are not in focus for this stage of the } \\
\text { prototype. }\end{array}$ \\
\hline 2 & $\begin{array}{l}\text { Speech-User- } \\
\text { Interaction }\end{array}$ & $\begin{array}{l}\text { The IPA should give a voice-feedback in the context of the triggered } \\
\text { command and request missing parameters to fulfil the command. }\end{array}$ \\
\hline 3 & $\begin{array}{l}\text { Explanation- } \\
\text { Mode }\end{array}$ & $\begin{array}{l}\text { The IPA should be able to cluster data, label and rate KPIs and give a } \\
\text { brief summary of the data, which are displayed as a chart and explain } \\
\text { the main points to the user via speech synthesis. } \\
\text { Limitation: The type of report is already known, and the data-content } \\
\text { is classified by a configuration. Query Detail-Information for a specific } \\
\text { cluster is not supported. }\end{array}$ \\
\hline
\end{tabular}

Source: Authors' work

\section{Artifact features}

For information retrieval, the user can ask the system for a brief summary (Feature set F1), triggered by one of the defined keywords "briefing" or "summary" the system matches the briefing-command and starts gathering information, such as notes to customers written by other ERP system-users. For example, a note created by the fictitious user Melanie Becker on 8th February 2020 at a fictitious customer FOM Düsseldorf will be read out like that:

"Note by Melanie Becker on February 8, 2020, 01:42 p.m. at FOM Düsseldorf.

Contact person: Mr Rüdiger Buchkremer.

Subject: Interest in ERP-system.

Content: The director of the Institute for IT Management and Digitization Prof. Dr Buchkremer called and requested information on the ERP system."

Important details are submitted via speech-synthesis, to get a brief summary about relevant information about interests and customers. As an example for task execution, a command for creating notes was implemented (Feature set F2). Triggered by the keyword "create note", followed by a company name, the ERP system starts to search for the company, opens the note-formula and listens to the user's voice to gather the content of the note via speech-to-text. In addition to simple workflows, a complex command-setup was implemented for information retrieval and user-interaction using the explanation mode of the IPA. Triggered by the keywords "current situation" the IPA presents a graphic report (see Figure 3), showing the profit margin of the company and starts to explain the figures including a preconfigured interpretation of the value ranges for relevant key performance indicators (Feature set F3). 
Figure 3

Report contribution margin

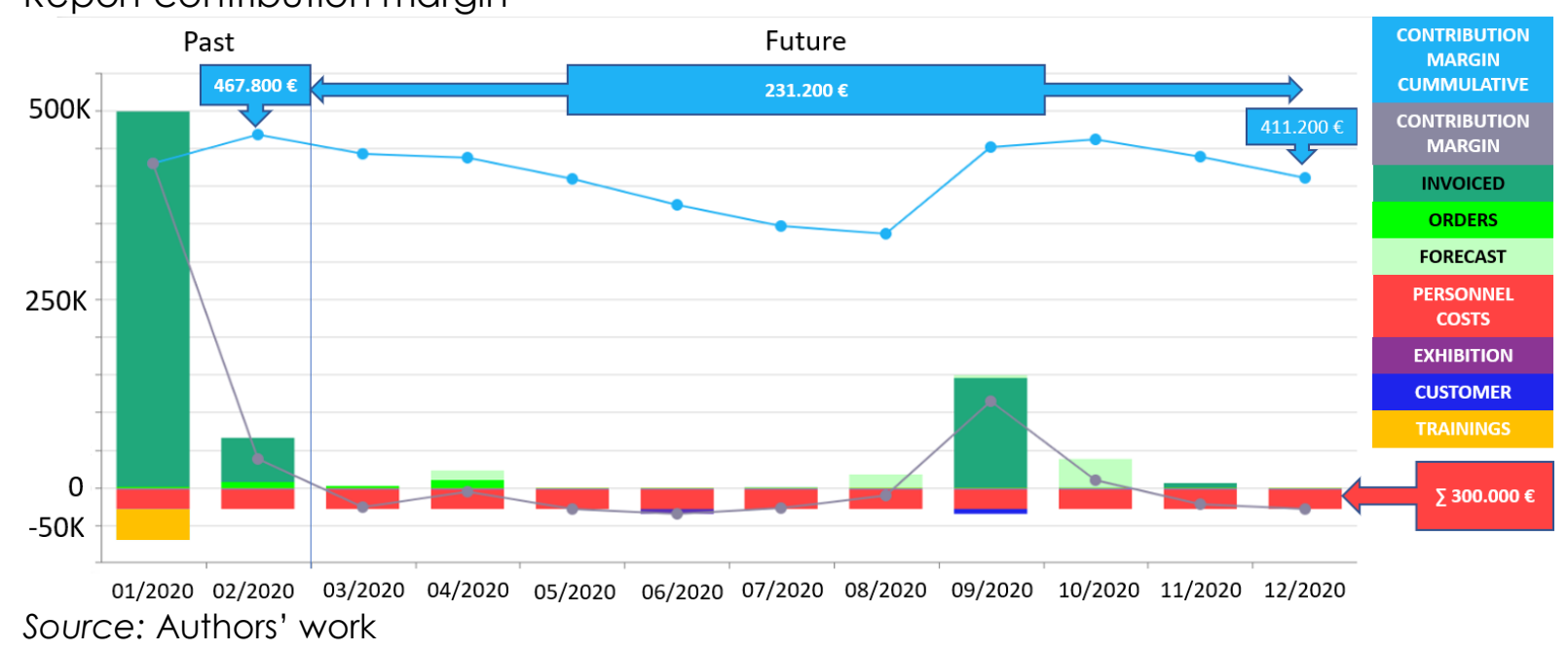

Via speech synthesis, the system will read out the following information and highlight important coordinate points in the chart to attract the user's attention.

"The current situation of the company is as follows: In the past, January until February 2020 approx. $467.800 €$ as contribution margin. For the future March to December 2020, about $231.200 €$ are expected as contribution margin. For the entire period, January to December 2020 is the expected contribution margin approx. 411,200€. The contribution margin is higher than the shareholder expectations. The highest costs are caused by personnel costs: $300.000 €$. Personnel costs are below the planned budget."

The user is also able to comprehend the summary with a drill-down triggered by the command "show me details for", followed by the name of the month, e.g. January. The IPA shows a grid with detailed information about the costs and revenues in the requested date span as presented in Figure 4 and retrieves more details about the background of the displayed report. With these details, the user can gain deep insights of the revenue- and cost structure of the company, for example, the level of personnel costs (highlighted red) or very profitable projects (highlighted green).

This feature enables the user for data-driven decisions in combination with their own intuition leading to data-informed decision making (Potančok, 2019). Since this research direction is still new, it is necessary to be noted that business intelligence (BI) on its own is not able to increase the organisation's performance, but the combination of $\mathrm{Bl}$ and business process management - when both are aligned - are giving a business value (Suša Vugec et al., 2020). 
Figure 4

Drill-Down function for details on period January 2020

\begin{tabular}{|c|c|c|c|c|c|}
\hline PERIOD & TYPE & REFERENCE & PROCEEDS & costs & $\begin{array}{l}\text { CONTRIBUTION } \\
\text { MARING }\end{array}$ \\
\hline $01 / 2020$ & INVOICED & PO\#: 10000 & $435.000 €$ & $5.000 €$ & $430.00 €$ \\
\hline $01 / 2020$ & INVOICED & PO\#: 20000 & $15.000 €$ & $5.000 €$ & $10.000 €$ \\
\hline $01 / 2020$ & INVOICED & PO\#: 30000 & $50.000 €$ & $10.000 €$ & $40.000 €$ \\
\hline $01 / 2020$ & $\begin{array}{l}\text { PERSONELL } \\
\text { COSTS }\end{array}$ & TEAM 1 & & $15.000 €$ & $-15.000 €$ \\
\hline $01 / 2020$ & $\begin{array}{l}\text { PERSONELL } \\
\text { COSTS }\end{array}$ & TEAM 2 & & $10.000 €$ & $-10.000 €$ \\
\hline $01 / 2020$ & TRAININGS & TEAM 2 & & $30.000 €$ & $-30.000 €$ \\
\hline$\Sigma$ & & & $500.000 €$ & $175.000 €$ & $425.00 €$ \\
\hline
\end{tabular}

Source: Authors' work

\section{Artifact evaluation}

The main research design has been discussed in the course of a scientific conference (Hüsson \& Holland, 2019b). To evaluate the IPA-artifact a questionnaire is derived from the implemented features enabling the participant to rate the usefulness of single features according to a four-point Likert scale ranged from strongly agree to strongly disagree (Lozano et al., 2008). Since there is no neutral answer-option the participants have to decide whether they agree or disagree with the usefulness of a feature (Nowlis et al., 2002). The authors choose this option to get a clear positive or negative rating of the specific feature regarding the usefulness. For each feature-set, the participant was able to give a separate free text written feedback in a commentsection.

The questionnaire for feature evaluation was online available from 15.11.2019 till 31.01.2020. The link was sent to 400 ERP system-users from an internal mailing list and 100 users with research-background. The questionnaire provided a link to a video with a brief description of the IPAs-features and a link for direct access to the demoenvironment for an individual experience of the IPA in a simulated production system.

The survey was structured in three parts:

1. Demographic characteristics like gender and job information

2. Characteristics in experience with technology (IPA and ERP)

3. feature-rating and comments

The independent variables have to be derived from researches in the field of private use of IPAs (Jiang et al., 2015; Kiseleva et al., 2016; Han \& Yang, 2018; Yang \& Lee, 2019) based on missing comparable business studies of IPA the existing findings have to extend the business perspective. The supposed dependent variables must be derived based on technical framework recommendations (Zhou, 2016) in combination with feature-ratings in a private context and business needs (Saad et al., 2017). On the other hand, the main goal of the survey is to identify the most useful features to get a solid foundation for further improvements of the artifact in order to contribute to the rigour cycle of the design science research. Since previous studies identified the task attraction as the main driver for usefulness and continues intention in private use (Han \& Yang, 2018; Lopatovska et al., 2019), the expectation for the outcome is a not significant correlation in a business context too. To approve the 
expected outcome the correlations will be analysed in the result chapter with the aid of a correlation matrix.

Table 2

Characteristics and theoretical foundation

\begin{tabular}{|c|c|}
\hline Characteristics & theoretical foundation \\
\hline Gender (GQ1), Age (GQ2) & Comparable study (Han \& Yang, 2018) \\
\hline Personnel responsibility (GQ3) & Derived from occupation (Han \& Yang, 2018) \\
\hline Job position (GQ4) & Comparable study (Luger \& Sellen, 2016) \\
\hline Industry (GQ5) & Comparable study (Lambeck et al., 2014b) \\
\hline Experience with Voice-Assistants (GQ6) & $\begin{array}{l}\text { Derived from technology expertise (McLean } \\
\text { \& Osei-Frimpong, 2019) and Experience (Brill } \\
\text { et al., 2019) }\end{array}$ \\
\hline Open for new technology (GQ7) & $\begin{array}{l}\text { Derived from study of attitudes towards } \\
\text { technology (Edison \& Geissler, 2003) and } \\
\text { technology optimism from comparable study } \\
\text { (Kowalczuk, 2018) }\end{array}$ \\
\hline Participant type (GQ8) & Comparable study (Kiseleva et al., 2016) \\
\hline Experience with ERP systems (GQ9) & $\begin{array}{l}\text { Derived from technology expertise (McLean } \\
\text { \& Osei-Frimpong, 2019) }\end{array}$ \\
\hline ERP system (GQ10) & Comparable study (Lambeck, et al., 2014b) \\
\hline $\begin{array}{l}\text { Current tasks will change in future due to } \\
\text { new technology (GQ11) }\end{array}$ & $\begin{array}{l}\text { Derived from studies about the impact of } \\
\text { technology on the future of work (Betz et al., } \\
\text { 2019; Kaplan \& Haenlein, 2019) }\end{array}$ \\
\hline Percentage of repetitive activities (GQ12) & $\begin{array}{l}\text { Derived from GQ1 l as an indicator for } \\
\text { automation potential and a mediator for } \\
\text { impact on current tasks, since repetitive } \\
\text { activities have a higher risk of automation } \\
\text { (Grace et al., 2018). }\end{array}$ \\
\hline
\end{tabular}

Source: Authors' work

Table 3

Feature sets and theoretical foundation

\begin{tabular}{|c|c|}
\hline Feature set & theoretical foundation \\
\hline $\begin{array}{l}\text { Summary-Function (Feature set F1) } \\
\text { Gives a short summary of the information of the day } \\
\text { recorded in the system }\end{array}$ & $\begin{array}{l}\text { Information retrieval derived from } \\
\text { comparable studies (lannizzotto et al., 2018; } \\
\text { Ammari et al., 2019) }\end{array}$ \\
\hline $\begin{array}{l}\text { Entry-Function (Feature set F2) } \\
\text { Open masks and enter content via voice input }\end{array}$ & $\begin{array}{l}\text { Derived from functions like calendar entries } \\
\text { and chatbots (Jain et al., 2018; Lang et al., } \\
\text { 2018; Kaplan \& Haenlein, 2019) }\end{array}$ \\
\hline $\begin{array}{l}\text { Explanation-Function for reports } \\
\text { (Feature set } 3 \text { ) } \\
\text { Explains components of reports and evaluates key } \\
\text { figures via voice output }\end{array}$ & $\begin{array}{l}\text { Derived from a study in the field of data } \\
\text { analysis (Collins et al., 2018) }\end{array}$ \\
\hline $\begin{array}{l}\text { Other Features (Feature set } 4 \text { ) } \\
\text { Additional not yet fully implemented features: } \\
\text { worktime recording, search and prediction }\end{array}$ & $\begin{array}{l}\text { Derived from function suggestions (Zhou, } \\
\text { 2016) }\end{array}$ \\
\hline
\end{tabular}

Source: Authors' work

To avoid missing values the structure of the questionnaire does not allow empty answers for important items. Out of the 500 possible participants, more than $10 \%$ of respondents successfully completed the survey, resulting in a total of 66 respondents. Due to the complexity of the survey and the required ERP-knowledge in combination with IPA experience to judge the usefulness of the features a respondent rate of 13,2 
\% can be regarded as sufficient for a meaningful analysis (Delice, 2010; Fosnacht et al., 2017).

\section{Results}

The sample characteristics as worked out in Table 2 and 3 are now displayed in relation to the sample in Table 4 and 5. The evaluation shows that more than $90 \%$ of the participants have experiences with ERP systems and approximately $80 \%$ have experience with voice-assistants. More than $74 \%$ watched the tutorial video and roughly $35 \%$ tried out the artifact in a simulated production system. More than $92 \%$ of all participants expect, that new technologies (Compare Sum of percentage in GQ1 1 in Table 5) will have an impact on their work tasks. This result aligns with other research results (Baccala et al., 2018; Betz et al., 2019), but surprisingly even participants with a low proportion of repetitive activities (23 participants with less than $20 \%$ ), agree or partially agree, that their work will be affected, only one participant in this characteristic answered with rather not true.

Table 4

Demographic characteristics

\begin{tabular}{|c|c|c|}
\hline \multirow[t]{2}{*}{ Characteristics } & \multicolumn{2}{|c|}{ Respondents $(\mathrm{n}=66$ ) } \\
\hline & Number & Percentage \\
\hline \multicolumn{3}{|l|}{ Gender (GQ1) } \\
\hline Male & 46 & 69,70 \\
\hline Female & 20 & 30,30 \\
\hline \multicolumn{3}{|l|}{ Age (GQ2) } \\
\hline $18-25$ & 6 & 9,09 \\
\hline $26-35$ & 26 & 39,39 \\
\hline $36-45$ & 12 & 18,18 \\
\hline $46-55$ & 15 & 22,73 \\
\hline$>55$ & 7 & 10,61 \\
\hline \multicolumn{3}{|l|}{ Personnel responsibility (GQ3) } \\
\hline Yes & 31 & 46,97 \\
\hline No & 35 & 53,03 \\
\hline \multicolumn{3}{|l|}{ Job position (GQ4) } \\
\hline Assistance & 1 & 1,52 \\
\hline Clerk / Employee & 25 & 37,88 \\
\hline Executive employee / team leader & 10 & 15,15 \\
\hline Head of department & 8 & 12,12 \\
\hline Management & 4 & 6,06 \\
\hline No Answer & 18 & 27,27 \\
\hline \multicolumn{3}{|l|}{ Industry (GQ5) } \\
\hline IT & 30 & 45,45 \\
\hline Service & 16 & 24,24 \\
\hline Others & 20 & 30,30 \\
\hline
\end{tabular}

Source: Authors' work

The demographic characteristics presented in Table 4 are in line with previous researches, stating that the IPA market is in an early stage (Han \& Yang, 2018) and attracting early adopters which are usually younger (Everett, 1995) and new technology attracts more male than female participants (Dobscha, 2003; Kotzé et al., 2016). The importance of the attitude towards technology is also underpinned by the result of the survey, all participants agreed or partially agreed, that they are open for new technologies (GQ7). 
Table 5

IT experience of respondents

\begin{tabular}{|c|c|c|}
\hline \multirow[t]{2}{*}{ Characteristics } & \multicolumn{2}{|c|}{ Respondents $(n=66)$} \\
\hline & Number & Percentage \\
\hline \multicolumn{3}{|l|}{ Experience with Voice-Assistants (GQ6) } \\
\hline Yes & 54 & 81,82 \\
\hline No & 12 & 18,18 \\
\hline \multicolumn{3}{|l|}{ Open for new technology (GQ7) } \\
\hline I agree & 53 & 80,30 \\
\hline I partially agree & 13 & 19,70 \\
\hline \multicolumn{3}{|l|}{ Participant type (GQ8) } \\
\hline Watched the video and tried the IPA & 17 & 25,76 \\
\hline Tried the IPA only & 7 & 10,61 \\
\hline Watched the video only & 32 & 48,48 \\
\hline Either watched or tried the IPA & 10 & 15,15 \\
\hline \multicolumn{3}{|l|}{ Experience with ERP systems (GQ9) } \\
\hline User & 12 & 18,18 \\
\hline User with advanced knowledge & 11 & 16,67 \\
\hline Key-User (expert for process areas) & 7 & 10,61 \\
\hline Administrator (expert for configuration) & 7 & 10,61 \\
\hline Key-User and Administrator & 15 & 22,73 \\
\hline No Experience & 6 & 9,09 \\
\hline \multicolumn{3}{|l|}{ ERP system (GQ10) } \\
\hline Vemas.NET & 39 & 59,09 \\
\hline SAP & 10 & 15,15 \\
\hline None & 10 & 15,15 \\
\hline Microsoft Dynamics & 3 & 4,55 \\
\hline Others & 16 & 24,24 \\
\hline \multicolumn{3}{|c|}{ Current tasks will change in future due to new technology (GQ11) } \\
\hline I agree & 39 & 59,09 \\
\hline I partially agree & 22 & 33,33 \\
\hline Rather not true & 4 & 6,06 \\
\hline I disagree & 1 & 1,52 \\
\hline \multicolumn{3}{|l|}{ Percentage of repetitive activities (GQ12) } \\
\hline$<20 \%$ & 23 & 34,84 \\
\hline ...between $20 \%$ and $50 \%$ & 37 & 56,06 \\
\hline$>50 \%$ & 6 & 9,09 \\
\hline
\end{tabular}

Source: Authors' work

Based on their personal impression of the IPA the participants rated the features regarding the usefulness and had the opportunity to vote for further features. The results are presented in Table 6.

With $87,9 \%$ positive votes (I agree or I partially agree) F4.4 - speech-search is the best-rated feature, followed by F2.2 -speech-input at $84,9 \%$ and F2.1 - speech navigation at $84,8 \%$. After a top-down analysis leading to the descriptive results presented, the survey results are analysed to investigate the quality dimensions in the area of usability. 
Table 6

IPA-feature rating $(\mathrm{n}=66)$

\begin{tabular}{|c|c|c|c|c|}
\hline Summary-Function (Feature set $\mathrm{F} 1$ ) & I agree & $\begin{array}{l}\text { I partially } \\
\text { agree }\end{array}$ & $\begin{array}{l}\text { I partially } \\
\text { disagree }\end{array}$ & I disagree \\
\hline $\begin{array}{l}\text { The daily summary of the processes informs } \\
\text { me specifically for my tasks } \\
\text { (Feature F1.1 - daily summary) }\end{array}$ & $36,36 \%$ & $33,33 \%$ & $22,73 \%$ & $7,58 \%$ \\
\hline $\begin{array}{l}\text { The IPA should compress the notes of the users } \\
\text { again and output only keywords } \\
\text { (Feature F1.2- daily summary compressed) }\end{array}$ & $19,7 \%$ & $36,36 \%$ & $27,27 \%$ & $16,67 \%$ \\
\hline $\begin{array}{l}\text { It should be possible to output more } \\
\text { information, such as the number of open and } \\
\text { completed hotline tickets, number of } \\
\text { documents created } \\
\text { (Feature F1.3 - daily summary extended) }\end{array}$ & $40,91 \%$ & $31,82 \%$ & $15,15 \%$ & $12,12 \%$ \\
\hline \multicolumn{5}{|l|}{ Entry-Function (Feature set F2) } \\
\hline $\begin{array}{l}\text { Calling up the mask via voice command } \\
\text { enables faster acquisition } \\
\text { (Feature } \mathbf{F 2 . 1} \text { - speech navigation) }\end{array}$ & $39,39 \%$ & $45,45 \%$ & $4,55 \%$ & $10,61 \%$ \\
\hline $\begin{array}{l}\text { The possibility to enter the textual content via } \\
\text { speech simplifies the input } \\
\text { (Feature } \mathbf{F} \mathbf{2} \mathbf{2} \text {-speech-input) }\end{array}$ & $57,58 \%$ & $27,27 \%$ & $3,03 \%$ & $12,12 \%$ \\
\hline $\begin{array}{l}\text { Speech recording in all masks with input fields } \\
\text { for longer texts is helpful } \\
\text { (Feature F2.3 - Speech-Input long text) }\end{array}$ & $51,52 \%$ & $28,79 \%$ & $4,55 \%$ & $15,15 \%$ \\
\hline \multicolumn{5}{|l|}{$\begin{array}{l}\text { Explanation-Function for reports } \\
\text { (Feature set } 3 \text { ) }\end{array}$} \\
\hline $\begin{array}{l}\text { The combination of language interaction in } \\
\text { graphical and tabular overviews promotes } \\
\text { the understanding of the displayed content } \\
\text { (Feature F3.1 - explanation) }\end{array}$ & $57,58 \%$ & $21,21 \%$ & $15,15 \%$ & $6,06 \%$ \\
\hline $\begin{array}{l}\text { The pre-evaluation of the key figures via voice } \\
\text { output influences my own decision making } \\
\text { (Feature F3.2 - explanation influence) }\end{array}$ & $15,15 \%$ & $40,91 \%$ & $33,33 \%$ & $10,61 \%$ \\
\hline $\begin{array}{l}\text { The graphical and tabular views are sufficient } \\
\text { for me, I do not need any linguistic } \\
\text { preparation } \\
\text { (Feature F3.3 - no explanation) }\end{array}$ & $30,3 \%$ & $42,42 \%$ & $16,67 \%$ & $10,61 \%$ \\
\hline \multicolumn{5}{|l|}{ Other Features (Feature set 4) } \\
\hline $\begin{array}{l}\text { The recording of working hours via voice input } \\
\text { would make my work easier } \\
\text { (Feature } \mathbf{F 4 . 1} \text { - worktime recording) }\end{array}$ & $31,82 \%$ & $24,24 \%$ & $21,21 \%$ & $22,73 \%$ \\
\hline $\begin{array}{l}\text { Voice commands can completely replace } \\
\text { navigation via keyboard, mouse or touch } \\
\text { screen (Feature } \mathbf{F} \mathbf{4} \mathbf{2} \text { - replace keyboard) }\end{array}$ & $9,1 \%$ & $22,7 \%$ & $37,9 \%$ & $30,3 \%$ \\
\hline $\begin{array}{l}\text { Forecasts and predictions e.g. of expected } \\
\text { sales figures (predictive analytics) can be } \\
\text { better understood through the combination } \\
\text { of graphical representation and speech } \\
\text { interaction } \\
\text { (Feature } \mathbf{F} 4.3 \text { - prediction) }\end{array}$ & $37,88 \%$ & $37,88 \%$ & $10,61 \%$ & $13,64 \%$ \\
\hline $\begin{array}{l}\text { A search function to open customers, } \\
\text { prospects or contacts directly by voice } \\
\text { speeds up the process of finding information } \\
\text { (Feature } \mathbf{F} 4.4 \text { - speech-search) }\end{array}$ & $56,06 \%$ & $31,82 \%$ & $4,55 \%$ & $7,58 \%$ \\
\hline
\end{tabular}

Source: Authors' work 
Table 7

Correlation Matrix nominal characteristics and ordinal features

\begin{tabular}{|c|c|c|c|c|c|c|c|c|c|c|c|}
\hline & $M$ & SD & GQ2 & GQ3 & GQ4 & GQ6 & GQ7 & GQ8 & GQ9 & GQ11 & GQ12 \\
\hline Age (GQ2) - Clustered & 2.86 & 1.19 & & & & & & & & & \\
\hline $\begin{array}{l}\text { Personnel responsibility } \\
\text { (GQ3) }\end{array}$ & 0.47 & 0.50 & .17 & & & & & & & & \\
\hline Job position (GQ4) & 2.02 & 1.52 & -.02 & $.28^{*}$ & & & & & & & \\
\hline IPA experience (GQ6) & 0.82 & 0.39 & -.05 & .13 & -.14 & & & & & & \\
\hline New technology (GQ7) & 1.20 & 0.40 & -.04 & -.08 & .03 & -.06 & & & & & \\
\hline Participant type (GQ8) & 1.47 & 1.04 & .03 & -.13 & .15 & -.11 & -.20 & & & & \\
\hline ERP experience (GQ9) & 2.42 & 1.85 & $.34^{* *}$ & .14 & $.31^{*}$ & -.22 & -.04 & .23 & & & \\
\hline $\begin{array}{l}\text { Technology impact } \\
\text { (GQ11) }\end{array}$ & 1.50 & 0.69 & .09 & .04 & -.05 & -.12 & .22 & .13 & -.04 & & \\
\hline $\begin{array}{l}\text { Repeating activities } \\
\text { (GQ12) }\end{array}$ & 1.74 & 0.62 & $-.30^{*}$ & .12 & -.01 & -.06 & $.26^{*}$ & $-.36^{* *}$ & -.20 & .01 & \\
\hline Daily summary (F1.1) & 2.02 & 0.95 & .08 & .13 & -.06 & .07 & -.17 & -.08 & .13 & $.28^{*}$ & -.04 \\
\hline $\begin{array}{l}\text { Daily summary } \\
\text { compressed (F1.2) }\end{array}$ & 2.41 & 0.99 & .03 & -.03 & .03 & .06 & -.20 & -.13 & -.12 & -.04 & -.08 \\
\hline $\begin{array}{l}\text { Daily summary extended } \\
\text { (F1.3) }\end{array}$ & 1.98 & 1.03 & .09 & .24 & -.01 & -.14 & .07 & -.22 & .09 & -.07 & .05 \\
\hline Speech navigation (2.1) & 1.80 & 0.81 & .08 & .07 & -.14 & .02 & -.02 & -.12 & -.13 & .01 & .04 \\
\hline Speech input (F2.2) & 1.61 & 0.82 & -.03 & -.04 & -.09 & -.22 & .03 & -.08 & -.04 & .10 & -.03 \\
\hline $\begin{array}{l}\text { Speech input long text } \\
\text { (F2.3) }\end{array}$ & 1.73 & 0.89 & -.15 & -.14 & .06 & $-.27^{*}$ & .14 & -.17 & -.08 & .07 & .03 \\
\hline Explanation (F3.1) & 1.70 & 0.94 & $.46^{* * *}$ & $.29 *$ & -.02 & -.14 & -.04 & $-.29 *$ & .03 & .19 & -.04 \\
\hline $\begin{array}{l}\text { Explanation influence } \\
\text { (F3.2) }\end{array}$ & 2.39 & 0.87 & $.34^{* *}$ & $.33^{* *}$ & .01 & -.03 & .00 & -.18 & .18 & .22 & -.02 \\
\hline $\begin{array}{l}\text { No explanation (F3.3) - } \\
\text { Inverted }\end{array}$ & 2.92 & 0.95 & .07 & -.10 & .07 & -.19 & .13 & $-.32^{* *}$ & .18 & .03 & .20 \\
\hline Worktime recording (F4.1) & 2.35 & 1.16 & .05 & .20 & .10 & -.06 & -.15 & $-.24^{*}$ & .03 & -.13 & .05 \\
\hline Replace keyboard (F4.2) & 2.89 & 0.95 & .18 & .00 & $-.24^{*}$ & .18 & -.19 & -.03 & .21 & .16 & -.08 \\
\hline Prediction (F4.3) & 2.00 & 1.02 & $.32^{* *}$ & .15 & .08 & .01 & .03 & $-.45^{* * *}$ & .14 & .22 & -.03 \\
\hline Speech search (F4.4) & 1.64 & 0.89 & -.17 & .03 & -.07 & .20 & -.16 & $-.30 *$ & $-.26 *$ & -.05 & .10 \\
\hline
\end{tabular}

Source: Authors' work

Note: $p<.001^{* * *} p<.01{ }^{* *} p<.05^{*}$

Table 7(continued)

Correlation Matrix nominal characteristics and ordinal features

\begin{tabular}{|c|c|c|c|c|c|c|c|c|c|c|c|c|}
\hline & F1.1 & F1.2 & F1.3 & F2.1 & F2.2 & F2.3 & F3.1 & F3.2 & F3.3 & F4.1 & F4.2 & F4.3 \\
\hline $\begin{array}{l}\text { Daily summary } \\
\text { compressed } \\
\text { (F1.2) }\end{array}$ & .24 & & & & & & & & & & & \\
\hline $\begin{array}{l}\text { Daily summary } \\
\text { extended (F1.3) }\end{array}$ & $.38^{* *}$ & .23 & & & & & & & & & & \\
\hline $\begin{array}{l}\text { Speech } \\
\text { navigation (2.1) }\end{array}$ & .14 & .04 & .20 & & & & & & & & & \\
\hline $\begin{array}{l}\text { Speech input } \\
\text { (F2.2) }\end{array}$ & .10 & .08 & .19 & $.57^{* * *}$ & & & & & & & & \\
\hline $\begin{array}{l}\text { Speech input } \\
\text { long text (F2.3) }\end{array}$ & .23 & .11 & $.38^{* *}$ & $.35^{* *}$ & $.67^{* * *}$ & & & & & & & \\
\hline $\begin{array}{l}\text { Explanation } \\
\text { (F3.1) }\end{array}$ & $.36^{* *}$ & .10 & $.31^{*}$ & .11 & .05 & .16 & & & & & & \\
\hline $\begin{array}{l}\text { Explanation } \\
\text { influence (F3.2) }\end{array}$ & $.56^{* * *}$ & .16 & $.46^{* * *}$ & .21 & .16 & $.26^{*}$ & $.58^{* * *}$ & & & & & \\
\hline $\begin{array}{l}\text { No explanation } \\
\text { (F3.3) - Inverted }\end{array}$ & .24 & -.02 & .15 & -.13 & -.06 & .10 & .19 & $.28^{*}$ & & & & \\
\hline $\begin{array}{l}\text { Worktime } \\
\text { recording (F4.1) }\end{array}$ & $.37^{* *}$ & .22 & $.48^{* * *}$ & $.41^{* * *}$ & $.41^{* * *}$ & $.37^{* *}$ & .15 & $.37^{* *}$ & .08 & & & \\
\hline $\begin{array}{l}\text { Replace } \\
\text { keyboard (F4.2) }\end{array}$ & $.43^{* * *}$ & $.29 *$ & .16 & $.26^{*}$ & .23 & .17 & .06 & $.43^{* * *}$ & .06 & $.43^{* * *}$ & & \\
\hline Prediction (F4.3) & $.51^{* * *}$ & .22 & $.32 * *$ & .18 & $.24^{*}$ & $.32 * *$ & $.49^{* * *}$ & $.58^{* * *}$ & $.39 * *$ & $.29 *$ & $.27^{*}$ & \\
\hline $\begin{array}{l}\text { Speech search } \\
\text { (F4.4) }\end{array}$ & $.40 * * *$ & $.30^{*}$ & .24 & $.46^{* * *}$ & $.42^{* * *}$ & $.42^{* * *}$ & .23 & $.29 *$ & .15 & $.44^{* * *}$ & $.30^{*}$ & $.44^{* * *}$ \\
\hline
\end{tabular}

Source: Authors' work

Note: $p<.001^{* * *} p<.01{ }^{* *} p<.05^{*}$ 
A non-parametric correlation analysis by using spearman's rank-order correlation was done to assess the nature of the connection among the analysed variables. The item Gender (GQ1) as a binary variable was removed in order to avoid analysing correlations between binary and nominal variables (Gogtay \& Thatte, 2017). The items Industry (GQ5) and ERP system (G10) as nominal variables were removed from the matrix during the analysis, as no meaningful order for the evaluation can be established. The excluded characteristic can be useful for further analysis regarding differences between users of different ERP systems, but since nearly $60 \%$ of the participants are users of the ERP system Vemas.NET, more than $45 \%$ participants are in the IT-Industry and almost $70 \%$ of the participants are male, more samples ofespecially female users - of other ERP systems and industries have to be collected to perform a valid analysis. Item no explanation (F3.3) was inverted because the question was negated. The age (GQ2) was not collected as a numerical value due to data protection, but as a Likert scale with the following coding: 1: 18-25, 2: 26-35, 3: 36-45, 4: $46-55,5:>55$.

Table 7 presents the correlation matrix for nominal characteristics and ordinal feature variables of the survey. The cross-correlation within the features are only shown for the sake of completeness. The correlations between the features are not considered, as no relevant conclusions can be drawn. Spearman's correlation coefficients as a standardised and symmetric rank coefficient in $[-1,1]$ revealed the highest correlation with $r=.46$ is between age (GQ2) and F2.3 - Speech-Input long text and the highest negative correlation with $r=-.45$ is between participant type (GQ8) and F4.3 - Prediction. The presented maximum and minimum r-values from the correlation matrix are indicating the presumed weak correlation between the characteristics and the feature sets. More details regarding the descriptive analysis and the correlations will be discussed in the next chapter.

\section{Discussion}

The majority of the participants $(68,2 \%)$ agreed, that speech-input is not able to fully substitute input devices like keyboard, touchscreen or mouse, so the IPA is recognised as an addition to traditional input methods, especially for search-functions (F4.4 $87,9 \%$ ), speech-input (F2.2-84,9\%) and navigation (F2.1 -84,8\%). One explanation for this result might be that this type of usage is already well known by the personal use of IPA's, but surprisingly the summary-feature (F1.1), also well know from Amazon's Alexa, is only rated positively by $69,7 \%$ of the participants. Further research will show whether the request for the enrichment of the summary (F1.3 - 72,7\%) or a compressed summary (F1.2 - 56,1\%) will improve the user-acceptance.

The speech-interaction feature with explanation mode received a positive rating of $78,8 \%$, but surprisingly $72,7 \%$ of the participants also agreed, that there is no explanation via IPA necessary. Therefore, further research is needed to explain in which situation and specific context this feature is relevant. Since $75,8 \%$ agreed to the need for prediction in combination with an explanation further research is also necessary to analyse the key-indicators for an IPA in this business context in the area of predictive analytics. More than $56 \%$ of the participants agreed, that the preevaluation of the key figures (F3.2) will influence their decision-making, this underpins the importance of this feature and justifies further research in this area.

The correlation matrix showed that there are only weak correlations between the participant characteristics and the feature sets. Referring to the literature the approach of analysing correlations between nominal variables and ordinal variables measured with a Likert scale can be regarded as appropriate (Norman, 2010). The highest positive correlation between the characteristics and feature sets is within age 
(GQ2) and F3.1 - explanation with $r=.46$, indicating as implication step the older the participant, the higher the usefulness of the explanation feature. This outcome may contribute to the correlation between age (GQ2) and personnel responsibility (GQ3) with $r=.29$, indicating that the chance for being responsible for personnel increases with age, but the job position (GQ4) is not correlating ( $r=-.02)$ with the usefulness of the explanation feature (F3.1). From this, it follows a general statement that the function has a greater benefit for decision-makers is not valid. The highest negative correlation is within participant-type (GQ8) and F4.3 - prediction with $r=-.45$. This correlation is most probably not valid, because the participant-type expresses how the participant has made the experience with the artifact. The item only asks for the assessment of the usefulness for future implementation, so in fact, the user was not able to experience the prediction here delivering an estimation. This underpins the weak dependencies and justifies considering the functional evaluations as almost independent of the characteristics.

\section{Conclusion}

This paper aimed to analyse the usefulness of specific IPA-features to support complex workflows in a business context. As part of the feature set, a new function called explanation-mode was developed and introduced to the scientific community, as well as to the business world. For the purpose of this research, a survey was conducted with questions about individual characteristics, ERP- and IPA experience and ratings regarding specific and testable IPA features. By using descriptive statistics and a correlation matrix, the collected data were analysed and interpreted. As discussed in the previous chapter the correlation between the individual characteristics and the usefulness of the features is weak, so the conclusion aligns with other researches in the private environment (Han \& Yang, 2018), that satisfaction and continuance intention is mainly affected by the task attraction. Since expectations between private customers and business-users are different more studies in the area of IPA in businesscontext are necessary to clarify the main drivers for continuance intention for IPA in business cases. For that purpose, the IPA-artifact will be extended and requested features like the search-function (F.4.4) will be implemented and existing features like the summary-function (Fl.1) extended according to the user-request for more details and higher information density (F1.2 + Fl.3).

The explanation mode - as a new and so far, unknown feature - got a high rate of acceptance, but further researches are necessary to work out the impact on decisionmaking and usefulness in daily business tasks, because also more than $72 \%$ agreed, that there is no special need for an explanation. By implementing prediction (F 4.3) to the IPA, the usefulness of an explanation might increase. This will be verified within further studies.

Limitations that can be addressed in future research are that the IPA was only tested in German language and with a relatively small number of participants. For further research, the IPA will support English to increase the number of possible users.

The artifact in combination with the survey was able to provide deep insights into the user-acceptance of specific features in a business context. Based on this result further development of the artifact and more research is necessary to work out details about feature usage - especially the explanation mode - and key-indicators for acceptance to adequately answer the research question raised in this article. 


\section{References}

1. Amazon. (2019), "Alexa for business FAQs", available at: https://aws.amazon.com/alexaforbusiness/faqs/?ncl=h_Is (11 Nov 2019)

2. Ammari, T., Kaye, J., Tsai, J. Y., Bentley, F. (2019), "Music, search, and IOT: How people (really) use voice assistants", ACM Transactions on Computer-Human Interaction, Vol. 26 No. 3, Article 17.

3. Babic, S., Orehovacki, T., Etinger, D. (2018), "Perceived user experience and performance of intelligent personal assistants employed in higher education settings", 41 st International Convention on Information and Communication Technology, Electronics and Microelectronics, 21-25 May, IEEE, Opatija, pp. 830-834.

4. Baccala, M., Curran, C., Garrett, D., Likens, S., Rao, A., Ruggels, A., Shehab, M., (2018), "2018 Al predictions: 8 insights to shape business strategy", available at: https://www.pwc.es/es/home/assets/ai-predictions-2018-report.pdf (16 Jun 2020)

5. Betz, U. A., Betz, F., Kim, R., Monks, B., Phillips, F. (2019), "Surveying the future of science, technology and business - A 35 year perspective", Technological Forecasting and Social Change, Vol. 144, pp. 137-147.

6. Brill, T. M., Munoz, L., Miller, R. J. (2019), "Siri, Alexa, and other digital assistants: a study of customer satisfaction with artificial intelligence applications", Journal of Marketing Management, Vol. 35 No 15-16, pp. 1401-1436.

7. Budzinski, O., Noskova, V., Xijie, Z. (2018), "The brave new world of digital personal assistants: Benefits and challenges from an economic perspective", available at: https://papers.ssrn.com/sol3/papers.cfm?abstract_id=3306169 (16 Jun 2020)

8. Collins, C., Andrienko, N., Schreck, T., Yang, J., Choo, J., Engelke, U., Jena, A., Dwyer, T. (2018), "Guidance in the human-machine analytics process", Visual Informatics, Vol. 2 No. 3, pp.166-180.

9. Cowan, B. R., Pantidi, N., Coyle, D., Morrissey, K., Clarke, P., Al-Shehri, S., Earley, D., Bandeira, N. (2017), "“What can i help you with?": Infrequent users' experiences of intelligent personal assistants", 19th International Conference on Human-Computer Interaction with Mobile Devices and Services, 4-7 September, Association for Computing Machinery, Vienna, Article 43.

10. Davis, K. H., Biddulph, R., Balashek, S. (1952), "Automatic recognition of spoken digits", The Journal of the Acoustical Society of America, Vol. 24 No. 6, pp. 637-642.

11. Delice, A. (2010), "The sampling issues in quantitative research", Educational Sciences: Theory \& Practices, Vol. 10 No, 4, pp. 2001-2003.

12. Dobscha, S. (2003), "Special session summary introducing gender into the analysis of techno-consumption", Advances in Consumer Research, Vol. 30, pp. 91-93.

13. Doss, P., Pal, A., Paul, K. J. S. (2018), "Unified voice assistant and loT interface", International Journal of Engineering Science and Computing, Vol. 8 No. 10, pp. 1906119065.

14. Edison, S. W., Geissler, G. L. (2003), "Measuring attitudes towardsgeneral technology: Antecedents, hypotheses and scale development", Journal of Targeting, Measurement and Analysis for Marketing, Vol. 12, pp. 137-156.

15. ElFarmawi, W. (2019), "Challenges affecting the implementation of Enterprise Resource Planning (ERP) system: An analysis", Journal of Systems Integration, Vol. 10 No, 3, pp. 3543.

16. Everett, R. (1995), Diffusion of Innovations, Free Press, New York.

17. Fosnacht, K., Sarraf, S., Howe, E., Peck, L. K. (2017), "How Important are high response rates for college surveys?", The Review of Higher Education, Vol. 40 No. 2, pp. 245-265.

18. Gnewuch, U., Morana, S., Maedche, A. (2017), "Towards designing cooperative and social conversational agents for customer service", in 38th International Conference on Information Systems, 10-13 December, ROK, Seoul, pp. 1-13.

19. Gogtay, N. J., Thatte, U. M. (2017), "Principles of correlation analysis", Journal of Association of Physicians of India, Vol. 65, pp. 78-81.

20. Grace, K., Salvatier, J., Dafoe, A., Zhang, B., Evans, O. (2018), "When will ai exceed human performance? Evidence from Al experts", Journal of Artificial Intelligence Research, Vol. 62, pp. 729-754. 
21. Han, S., Yang, H. (2018), "Understanding adoption of intelligent personal assistants", Industrial Management \& Data Systems, Vol. 118 No. 3, pp. 618-636.

22. Hsu, C.-L., Yu, C.-Ch., Wu, C.-C. (2014), "Exploring the continuance intention of social networking websites: An empirical research", Information Systems and e-Business Management, Vol. 12, No. 2, pp. 139-163.

23. Hüsson, D. (2019a) "3. Data Science Forum - ganz im Zeichen der künstlichen Intelligenz an der FOM in Düsseldorf (3rd Data Science Forum - all about artificial intelligence at the FOM in Düsseldorf)", available at: https://www.fom-blog.de/2018/12/3-datascience-forum-mit-ifid-google-ibm-co-ganz-im-zeichen-der-kuenstlichen-intelligenzan-der-fom-in-duesseldorf/ (11 Nov 2019)

24. Hüsson, D. (2019b), "Künstliche Intelligenz in ERP-Systemen im Bereich Business Intelligence und Sprachassistenten (Artificial intelligence in ERP systems in the field of business intelligence and language assistants)", in Vemas.Inside 2019 Conference, Krefeld.

25. Hüsson, D., Holland, A. (2019a), "Intelligent personal assistant and reporting - Explaining data to users through speech synthesis a prototype for user voice interaction and descriptive analytics in a web-based ERP-System", in Heisig, P. (Ed.), Knowledge Management in Digital Work Environments - State-of-the-Art and Outlook, 10th Conference Professional Knowledge Management, 18-20 March, FHP Verlag, Potsdam, pp. 157-161.

26. Hüsson, D., Holland, A. (2019b), "Intelligent personal assistants in business processes: Evaluation of a prototype (V-IP-A)", in 32nd Bled eConference - Humanizing Technology for a Sustainable Society, 16-19 June, University of Maribor Press, Bled, pp. $1133-1145$.

27. Iannizzotto, G. et al. (2018), "A vision and speech enabled, customizable, virtual assistant for smart environments", 11th International Conference on Human System Interaction, 4-6 July, IEEE, Gdansk, pp. 50-56.

28. Jain, M., Kumar, P., Kota, R., Patel, S. N. (2018), "Evaluating and informing the design of chatbots", in DIS 2018: Designing Interactive Systems Conference, 9-13 June, Association for Computing Machinery, Hong Kond, pp. 895-906.

29. Jiang, J., Hassan Awadallah, A., Jones, R., Ozertem, U., Zitouni, I., Gurunath Kulkarni, R., Khan, O. Z (2015), "Automatic online evaluation of intelligent assistants", in 24th International Conference on World Wide Web, 18-22 May, ACM Press, New York, pp. 506-516.

30. Juang, B. H., Rabiner, L. R. (2004), "Automatic speech recognition - A brief history of the technology development", Elsevier Encyclopedia of Language and Linguistics, Vol. 50 No. 2, pp. 637-655.

31. Kalinic, Z., Marinkovic, V. (2016), "Determinants of users' intention to adopt mcommerce: an empirical analysis", Information Systems and e-Business Management, Vol. 14 No. 2, pp. 367-387.

32. Kaplan, A., Haenlein, M. (2019), "Siri, Siri, in my hand: Who's the fairest in the land? On the interpretations, illustrations, and implications of artificial intelligence", Business Horizons, Vol. 62 No. 1, pp. 15-25.

33. Kiseleva, J., Williams, K., Jiang, J., Hassan Awadallah, A., Crook, A. C., Zitouni, I., Anastasakos, T. (2016), "Understanding user satisfaction with intelligent assistants", in 2016 ACM on Conference on Human Information Interaction and Retrieval, 13-17 March, ACM Press, New York, pp. 121-130.

34. Knote, R., Janson, A., Söllner, M., Leimeister, J. M. (2019), "Classifying smart personal assistants: An empirical cluster analysis", in 52nd Hawaii International Conference on System Sciences, 8-1 1 January, University of Hawaii, Manoa, pp. 2024-2033.

35. Kotzé, T. G., Anderson, O., Summerfield, K. (2016), "Technophobia: Gender differences in the adoption of high-technology consumer products", South African Journal of Business Management, Vol. 47 No. 1, pp. 21-28.

36. Kowalczuk, P. (2018), "Consumer acceptance of smart speakers: A mixed methods approach", Journal of Research in Interactive Marketing, Vol. 12 No. 4, pp. 418-431. 
37. Lambeck, C., Fohrholz, C., Leyh, C., Supulniece, I., Müller, R. (2014b), "Commonalities and contrasts: An investigation of ERP usability in a comparative user study", in Avital, M., Marco, J., Leimeister, M., Shultze, U. (Eds.), 22nd European Conference on Information Systems, 9-11 June, Association for Information Systems. Tel Aviv, pp. 1-15.

38. Lambeck, C., Müller, R., Fohrholz, C., Leyh, C. (2014a), "(Re-)evaluating user interface aspects in ERP systems -- An empirical user study", 47th Hawaii International Conference on System Sciences, 6-9 January, IEEE, Waikoloa, pp. 396-405.

39. Lang, R. D., Benessere, L. E., Halverson, H. (2018), "Virtual assistants in the workplace: Real, not virtual pitfalls and privacy concerns", Journal of Internet Law, Vol. 21 No. 12, pp. 18-21.

40. Lopatovska, I., Rink, K., Knight, I., Raines, K., Cosenza, K., Williams, H., Sorsche, P., Hirsch, D., Li, Q., Martinez, A., (2019), "Talk to me: Exploring user interactions with the Amazon Alexa", Journal of Librarianship and Information Science, Vol. 51 No. 4, pp. 984-997.

41. Lozano, L. M., García-Cueto, E., Muñiz, J. (2008), "Effect of the number of response categories on the reliability and validity of rating scales", Methodology, Vol. 4 No. 2, pp. 73-79.

42. Luger, E., Sellen, A. (2016), "'Like having a really bad PA": The gulf between user expectation and experience of conversational agents", in $2016 \mathrm{CHI}$ Conference on Human Factors in Computing Systems, 7-12 May, ACM, New York, pp. 5286-5297.

43. Manikonda, L., Deotale, A., Kambhampati, S. (2017), "What's up with privacy?: User preferences and privacy concerns in intelligent personal assistants", 2018 AAAl/ACM Conference on Al, Ethics, and Society, 2-3 February, ACM, Honolulu, pp. 229-235.

44. McLean, G., Osei-Frimpong, K. (2019), "Hey Alexa ... examine the variables influencing the use of artificial intelligent in-home voice assistants", Computers in Human Behavior, Vol. 99, pp. 28-37.

45. Mohd Suki, N. N., Mohd Suki, N. N. (2017), "Flight ticket booking app on mobile devices: Examining the determinants of individual intention to use", Journal of Air Transport Management, Vol. 62, pp. 146-154.

46. Murad, C., Munteanu, C., Clark, L., Cowan, B. R. (2018), "Design guidelines for handsfree speech interaction", in 20th International Conference on Human-Computer Interaction with Mobile Devices and Services Adjunct, 3-6 September, ACM Press, New York, pp. 269-276.

47. Murad, C., Munteanu, C., Cowan, B. R., Clark, L. (2019), "Revolution or evolution? Speech interaction and $\mathrm{HCl}$ design guidelines", IEEE Pervasive Computing, Vol. 18 No. 2, pp. 33-45.

48. Nishimura, R., Yamamoto, D., Uchiya, T., Takumi, I. (2018), "Web-based environment for user generation of spoken dialog for virtual assistants", EURASIP Journal on Audio, Speech, and Music Processing, Vol. 1, Article 17.

49. Norman, G. (2010), "Likert scales, levels of measurement and the "laws" of statistics", Advances in Health Sciences Education, Vol. 15 No. 5, pp. 625-632.

50. Nowlis, S. M., Kahn, B. E., Dhar, R. (2002), "Coping with ambivalence: The effect of removing a neutral option on consumer attitude and preference judgments", Journal of Consumer Research, Vol. 29 No. 3, pp. 319-334.

51. Park, Y., Chen, J. V. (2007), "Acceptance and adoption of the innovative use of smartphone", Industrial Management \& Data Systems, Vol. 107 No. 9, pp. 1349-1365.

52. Peffers, K., Tuunanen, T., Niehaves, B. (2018), "Design science research genres: Introduction to the special issue on exemplars and criteria for applicable design science research", European Journal of Information Systems, Vol. 27 No. 2, pp. 129-139.

53. Potančok, M. (2019), "Role of data and intuition in decision making processes", Journal of Systems Integration, Vol. 10 No. 3, pp. 31-34.

54. Rzepka, C. (2019), "Examining the use of voice assistants: A value-focused thinking approach", in 25th Americas Conference on Information Systems, 15-17 August, Association for Information Systems, Cancún, pp. 1-10.

55. Saad, U., Afzal, U., El-Issawi, A., Eid, M. (2017), "A model to measure QoE for virtual personal assistant", Multimedia Tools and Applications, Vol. 76 No. 10, pp. 12517-12537. 
56. Saran, C. (2018), "Smart speakers: How to give apps a voice", available at: https://www.computerweekly.com/feature/Smart-speakers-How-to-give-apps-avoice (16 Jun 2020)

57. Sarikaya, R. (2017), "The technology behind personal digital assistants: An overview of the system architecture and key components", IEEE Signal Processing Magazine. Vol. 34 No. 1, pp. 67-81.

58. Sein, M. K., Henfridsson, O., Purao, S., Rossi, M., Lindgren, R. (2011), "Action design research", MIS Quarterly, Vol. 35 No. 1, pp. 37-56.

59. Shires, G., Jägenstedt, P. (2018), "Web Speech API", available at: https://w3c.github.io/speech-api/ (16 Jun 2020)

60. Venkatesh, V. (2000), "Determinants of perceived ease of use: Integrating control, intrinsic motivation, and emotion into the technology acceptance model", Information Systems Research, Vol. 11 No. 4, pp. 342-365.

61. Vugec, D. S., Vukšić, V. B., Bach, M. P., Jaklič, J., Štemberger, M. I. (2020), "Business intelligence and organizational performance", Business Process Management Journal, ahead-of-p(ahead-of-print), pp. 1-25. doi: 10.1 108/BPMJ-08-2019-0342.

62. Wedekind, K. (2018). "HTML5 speech recognition API", available at: https://codeburst.io/html5-speech-recognition-api-670846a50e92 (8 Dec 2018)

63. Wong, W., Veneziano, V., Mahmud, I. (2016), "Usability of enterprise resource planning software systems: An evaluative analysis of the use of SAP in the textile industry in Bangladesh", Information Development, Vol. 32 No. 4, pp. 1027-1041.

64. Yang, H., Lee, H. (2019), "Understanding user behavior of virtual personal assistant devices", Information Systems and e-Business Management, Vol. 17 No. 1, pp. 65-87.

65. Yang, H., YU, J., Zo, H., Choi, M. (2016), "User acceptance of wearable devices: An extended perspective of perceived value", Telematics and Informatics, Vol. 33 No. 2, pp. 256-269.

66. Zhou, Z. (2016), "A framework for virtual assistants: An exploratory study", International Journal of Social Science and Business, Vol. 1 No. 4, pp. 49-56. 


\section{About the authors}

Daniel Hüsson, M.A. is head of consulting at a German ERP system provider and advises customers in the area of process optimization. After completing a part-time bachelor's degree in business administration and a master's degree in business informatics, he is currently researching the use of artificial intelligence in processes of medium-sized companies in the service sector as part of a doctoral program at Universidad Católica San Antonio de Murcia Avda. de los Jerónimos, Spain (UCAM) in cooperation with FOM Essen, Germany. His research focuses on the use of intelligent personal assistants to control complex workflows and to prepare information in a userfriendly way. He is also research fellow at the Institute for IT Management \& Digitization (ifid). The author can be contacted at daniel.huesson@fom-net.de.

Alexander Holland is a Full-time professor at FOM University of Applied Sciences for information and process technologies and procedural programming technology. After successfully completing his studies in computer science at the University of Dortmund, Alexander Holland received his doctorate at the TU Dortmund University in 2008. Prior to this, he worked as a technical consultant and project manager for information and knowledge management at the computer group Hewlett-Packard between 1997 and 2001. Later he was a research assistant at the universities of Dortmund and Siegen. From 2007 to 2011 Holland was deputy director of the research center for knowledge management and intelligent systems at the University of Siegen. His research interests are computational intelligence, graphical modelling, decision theory, decision support systems, distributed systems, soft computing applications and relationship discovery in knowledge management. The author can be contacted at alexander.holland@fom.de.

Rocío Arteaga Sánchez is an Assistant Professor at UCAM (Catholic University of Murcia), Spain. She received her International PhD in Business Administration from the University of Huelva and she was visiting researcher at Cardiff University. Her research interests are centered on the impact of Internet on education, banking, e-commerce, and the acceptance and usage of new information technologies such as Moodle, WebCT, enterprise resource planning (ERP), social networks in education and business. She has published in leading journals including Computers \& Education, Computers in Human Behavior and Journal of Promotion Management. The author can be contacted at rarteaga@ucam.edu. 